\title{
Statistical concerns about the study: "Risk factors for polypharmacy in older adults in a primary care setting: a cross-sectional study"
}

This article was published in the following Dove Press journal:

Clinical Interventions in Aging

\section{Kubra Aydin' \\ Meryem Merve Oren ${ }^{2}$ \\ Tugba Aydin ${ }^{3}$}

'Ataturk University School of Medicine, Department of Internal Medicine, Division of Nephrology, Ataturk University, Yakutiye 25100, Erzurum, Turkey; ${ }^{2}$ Istanbul University, Istanbul Medical School, Department of Public Health, Capa 34390, Istanbul, Turkey; ${ }^{3}$ Istanbul Physical Medicine and Rehabilitation Training Hospital, Department of Physical Therapy and Rehabilitation, Bahcelievler 34/88, Istanbul, Turkey
Correspondence: Kubra Aydin Ataturk University School of Medicine, Department of Internal Medicine, Division of Nephrology, Ataturk University, Yakutiye 25100, Erzurum, Turkey

Tel +905324637I27

Fax +90 2125324208

Email mdkubraaydin@gmail.com

\section{Dear editor}

We read the article by Ersoy and Engin on the risk factors for polypharmacy in older adults in a primary care setting with great interest. ${ }^{1}$ We would like to add some comments that should improve the data interpretation in this large study.

Firstly, the authors noted that they assessed functionality by Activities of Daily Living and Instrumental Activities of Daily Living scales (ADL and IADL) with ADL consisting of five self-care measures, and IADL consisting of seven tasks. Scoring is undertaken using a 3-point ordinal scale, ranging from 0 to 2 . The 0 point indicates inability, 1 indicates ability to do the task with aid, and 2 indicates ability to do it independently. The maximum score is 10 for the ADL and 14 for the IADL. The authors referred to the articles by Katz et al in 1963 and Lawton and Brody in 1969. 2,3 However, Katz et al and Lawton and Brody's assessments were not evaluated with five and seven items, respectively, and they did not use the $0-2$ scale in the referenced articles. ${ }^{2,3}$ Instead, in the mentioned articles, ADL and IADL were assessed by six and eight items, respectively. Katz et al used an A to G scale to evaluate ADL and Lawton and Brody used a $0-1$ scale to evaluate IADL. Accordingly, the maximum scores were not 10 and 14 but A (Katz et al for ADL) and 8 (Lawton and Brody for IADL), respectively. Furthermore, to our knowledge, the method the authors applied for evaluation of ADL and IADL has not been validated, yet. Thus, the methodology they used to assess ADL and IADL should be clarified and noted as limitation of the study.

Secondly, some statistical flaws were observed. The authors stated that they used Pearson correlation test to assess association between daily drug consumption (DDC) and continuous variables. However, the mean DDC was given as $4.63 \pm 3.51$, with a very high SD value. This most probably suggests that the DDC parameter was a non-homogeneously distributed parameter. Hence, instead of Pearson correlation coefficient, Spearman Rho correlation should have been used. Similarly, while assessing the association between DDC and categorical variables such as presence of diabetes mellitus, metabolic syndrome, etc (as DDC seemed to be a non-homogenous parameter), the analyses should have been performed by Mann-Whitney $U$ test instead of Student's $t$-test. ${ }^{4-7}$

Additionally, under the data analysis heading, they noted that linear regression analysis was performed to analyze the risk factors for DDC. However, the dependent 
variable should have been a homogeneously distributed variable for a given linear regression analysis. Again, DDC did not seem to be a homogenous variable as it had a very high $\mathrm{SD}$ value. Thus, statistical analyses should be re-performed to enable the readers to obtain the correct results with consequent data interpretation.

\section{Disclosure}

The authors report no conflicts of interest in this communication.

\section{References}

1. Ersoy S, Engin VS. Risk factors for polypharmacy in older adults in a primary care setting: a cross-sectional study. Clin Interv Aging. 2018; 13:2003-2011.
2. Katz S, Ford AB, Moskowitz RW, Jackson BA, Jaffe MW. Studies of illness in the aged. The index of ADL: A standardized measure of biological and psychosocial function. JAMA. 1963;185:914-919.

3. Lawton MP, Brody EM. Assessment of older people: self-maintaining and instrumental activities of daily living. Gerontologist. 1969;9(3): 179-186.

4. Mukaka MM. Statistics corner: A guide to appropriate use of correlation coefficient in medical research. Malawi Med J. 2012;24(3):69-71.

5. Hart A. Mann-Whitney test is not just a test of medians: differences in spread can be important. BMJ. 2001;323(7309):391-393.

6. Pallant J. SPSS Survival Manual. UK: McGraw-Hill Education; 2005.

7. Field A. Discovering Statistics Using SPSS. 3rd ed. London: SAGE; 2009. 


\section{Authors' reply}

Suleyman Ersoy'

Velittin Selcuk Engin ${ }^{2}$

'Karabuk University, Faculty of Medicine, Department of Family Medicine, Karabuk 78050, Turkey; ${ }^{2}$ Ministry of Health, Melek Hatun Family Practice Center, Mevlanakapi, Istanbul 34340, Turkey

Correspondence: Suleyman Ersoy

Karabuk University, Faculty of Medicine, Department of Family Medicine, Alparslan Cad, Sirinevler, Karabuk 78050, Turkey

Tel +90505262 800I

Email suleymanersoy@gmail.com

Velittin Selcuk Engin

Melek Hatun Family Practice Center, Mevlanakapi, 19 Gumuscayiri

Sokak, Istanbul 34340, Turkey

Email sengin@istanbul.edu.tr

\section{Dear editor}

We have read the letter by Aydin et al regarding our article "Statistical concerns about the study: risk factors for polypharmacy in older adults in a primary care setting: a crosssectional study".

The authors raised two main objections. The first one is about Activities of Daily Living (ADL) and Instrumental Activities of Daily Living (IADL) scales.

Defining disability in functionally impaired people is complicated, especially in a heterogeneous population like older patients. Actually, there are plenty of functional ability instruments that have been developed to serve as a tool for objective assessment. In an effort to get more comprehensive and simpler tools, many ADL scales have been modified in terms of content and/or scoring system and Katz's ADL is not an exception. ${ }^{2}$ While less than fifty ADL scales were in use in the last century, ${ }^{3}$ now we are talking about three-digit numbers. ${ }^{4}$ Our comprehensive geriatric assessment kit includes scales which were adopted from geriatric clinics of different medical schools in the early 2000s. It is known, for ADL measurements, that most authors used to select items from existing scales and make some adjustments for their clinical practice. This situation has raised concerns about validity and reliability. ${ }^{5}$ Under these circumstances, we failed to match our ADL and IADL scales with the references. That resulted in discordance between given references and our application. We sincerely apologize to readers and thank the reviewers for spotting our mistake. However, although this situation renders our ADL and IADL measurements debatable, it would not be justifiable to say the same thing of our results, as findings regarding ADL and IADL scales are only ancillary and contributory to the study. We respectfully affirm that our main results and conclusions are uninfluenced by these measurements.
As for the statistics, we again thank the authors for their question. This allows us to share our response to reviewers with the readers in general. We agree that in small samples with abnormal distribution, nonparametric tests must be used; even though there are studies contrary to this common rule. These studies reported that type 1 errors in two-group comparisons are well controlled in all sample sizes even if distribution is not normal. ${ }^{6}$ Nonetheless, our sample size was far from controversial limits.

Our data were not normally distributed but were roughly normal. This was one of our main concerns. Our statistical consultants have concluded that, in studies with such large sample sizes, parametric tests are robust even if the distribution is not normal, as type 1 error rates do not differ. ${ }^{7}$ Our dependent variable is a continuous one and has a relatively large range (from 0 to 24). Regarding the data from 1,000 subjects, deviation from normality (according to the Kolmogorov-Smirnov test of normality) is something to be expected and does not exclude parametric tests as a choice.

In sample sizes $>100$, parametric tests such as Student's $t$-tests work well, even if the distribution is only approximately normal. ${ }^{8}$ Parametric tests have their advantages and we opted to use them.

\section{Disclosure}

The authors report no conflicts of interest in this communication.

\section{References}

1. Ersoy S, Engin VS. Risk factors for polypharmacy in older adults in a primary care setting: a cross-sectional study. Clin Interv Aging. 2018; 13:2003-2011.

2. Wallace M, Shelkey M. Reliability and validity of Katz ADL Index. Am J Nurs. 2008;108(4):64-72; quiz 71-72.

3. Feinstein AR, Josephy BR, Wells CK. Scientific and clinical problems in indexes of functional disability. Ann Intern Med 1986;105(3):413-420.

4. Lindeboom R, Vermeulen M, Holman R, De Haan RJ. Activities of daily living instruments: optimizing scales for neurological assessments. Neurology. 2003;60(5):738-742

5. Law M, Letts L. A critical review of scales of activities of daily living. Am J Occup Ther. 1989;43(8):522-528.

6. Poncet A, Courvoisier DS, Combescure C, Perneger TV. Normality and sample size do not matter for the selection of an appropriate statistical test for two-group comparisons. Methodology. 2016;12(2):61-71.

7. analyse-it.com [homepage on the Internet]. Central limit theorem and the normality assumption. Available from: https://analyse-it.com/docs/ user-guide/101/normalitycentrallimittheorem. Accessed November 20, 2018.

8. Marusteri M, Bacarea V. Comparing groups for statistical differences: how to choose the right statistical test? Biochem Medica. 2010;20(1) $15-32$. 
Dove Medical Press encourages responsible, free and frank academic debate. The content of the Clinical Interventions in Aging 'letters to the editor' section does not necessarily represent the views of Dove Medical Press, its officers, agents, employees, related entities or the Clinical Interventions in Aging editors. While all reasonable steps have been taken to confirm the content of each letter, Dove Medical Press accepts no liability in respect of the content of any letter, nor is it responsible for the content and accuracy of any letter to the editor.

Clinical Interventions in Aging

Dovepress

\section{Publish your work in this journal}

Clinical Interventions in Aging is an international, peer-reviewed journal focusing on evidence-based reports on the value or lack thereof of treatments intended to prevent or delay the onset of maladaptive correlates of aging in human beings. This journal is indexed on PubMed Central, MedLine,

CAS, Scopus and the Elsevier Bibliographic databases. The manuscript management system is completely online and includes a very quick and fair peer-review system, which is all easy to use. Visit http://www.dovepress. com/testimonials.php to read real quotes from published authors. 